\title{
Absolute and Conditional Application of Jus Sanguinis
}

\author{
Sattar Azizi ${ }^{1}$, Bijan Hajiazizi ${ }^{1}$ \& Razieh Hassankhani ${ }^{1}$ \\ ${ }^{1}$ Department of law, Bu-Ali Sina University, Hamedan, Iran \\ Correspondence: Razieh Hassankhani, Department of law, Bu-Ali Sina University, Hamedan, Iran. Tel: \\ 935-704-8617. E-mail: rzhasankhani@gmail.com
}

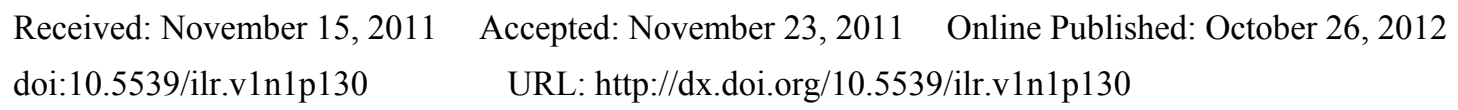

\begin{abstract}
Nationality is a political and spiritual relationship in attaching a person to a government. There are two criteria in granting nationality: Jus sanguinis (based on blood or descent) and Jus soli (based on birth place). Jus sanguinis (based on blood or descent) should be clarified; this article aims to clear one aspect of Jus sanguinis. It is focused on granting nationality based on Jus sanguinis from a generation to another which is called absolute application of Jus sanguinis. Although there is conditional application of Jus sanguinis which a part from parent's nationality other factors like domicile place or birth of parents are noticed as well in getting nationality conditional application of Jus sanguinis Maintains nation's correlation with society's norms.
\end{abstract}

Keywords: nationality, jus sanguinis, absolute, conditional

\section{Introduction}

Nationality, in political theory, is the qualities of belonging to a nation Personal naming practices exists in all human groups and are far from random. Rather, they continue to reflect social norms and ethno-cultural customs that have developed over generations (Mateos, 2011) in the sense of a group united by various strong ties. Among the usual ties are memberships in the same general community, common customs, culture, tradition, history, and language. (Weis, 1956)

Nationality determines the scope of application of basic rights and obligations of states vis-a '-vis other states and the international community, such as personal jurisdiction, the application of treaties and diplomatic protection. (Baubo“ck et al., 2006 A)

"Nationality is a relationship that connects and attributes one natural or legal person or one thing to a state" (Ameri, 1988)

"In state based on jus soli, because the territory s a major factor, the intellectuality of nationality is less important than jus sanguinis based states. Therefore we can state that nationality is not completely an intellectual relationship". (Nasiri, 2001)

Citizenship has three principles which have been described in article 15 of the universal declaration of human rights as follows: article 15:

Everyone has the right to a nationality.

No one shall be arbitrarily deprived of his nationality nor denied the right to change his nationality.

Citizenship based on how it emerged is divided into two main and acquisitive classes. In the main citizenship (nationality of origin), citizenship is imposed on the person by law from the beginning of birth. Two criteria of blood and soil are two ways to impose citizenship in this way, blood system is a way of imposing citizenship which will be imposed on the child by descent and soil system is a way which citizenship is determined from birthplace of individual.

Acquisitive citizenship (derivative) is a citizenship which a person studies during the life. It should be noted that this citizenship is not always optional and voluntary. They include change of little children citizenship whose parents change their citizenship and change of citizenship because of marriage.

Each of the main citizenship methods (blood and soil) has its own materials and interests including that we can transfer our interest to a country with a blood bond to the child through applying blood principle. But it should be said that none of the criteria of soil and blood have great performance including children of nation less parents 
(without nationality) through the blood principle suffer the fate of their parents and here the blood principle comes to help the soil principle.

Put like this, all countries with discretion and considering the interests and requirements of their community apply a system which is composed of two blood and soil principles for imposing citizenship to the child.

\section{Conditional and Absolute Application of Jus Sanguinis}

As we know the blood principle is one way to impose the main citizenship and in this way, the transmission of citizenship is through descent from parent to child. In this context a state may appear that someone immigrates outside his/her country and spent many years in a foreign country and owns children and grandchildren. With absolute apply of the blood principle it can be said that because the transmission of citizenship is through descent descendants of this individual for their ancestor citizenship will have the citizenship of a country where they not even have a very short period. This method of transmission citizenship through blood principle which is done without imposing any conditions is called absolute applies of blood principle. But the reviews on this topic comes to the conclusion that transmission of citizenship to a citizen for many generations is incorrect and obscene and leads to moving away from the goals and purposes of the blood principle which is assurance of Interest and commitment to the country. Thus the legislature because of some issues including the preservation of national cultural bond with the land in question Limit and bound granting citizenship to future generations of such people by the provisions to reach the desired target namely forming a society with people who have deep and genuine link with the desired community.

So to overcome this shortcoming, the conditional apply $\mathrm{f}$ the blood principle is expressed which the citizenship of the mentioned country is granted with terms and provisions to the second or third generation who have migrated from the country.

On this topic the terms of absolute and conditional apply of blood principle and manner of these constraints and conditions on some other legal systems are also expressed.

\section{Theory of Legal Scholars about Applying the Blood Principle}

The drafters of Harvard university plan said that granting citizenship based on blood principle to children of immigrants, who left their country, should not be unlimited. Based on this, Article 4 of this plan would require:

"A state may not confer its nationality at birth (jus sanguinis) upon a person born in the territory of another state, beyond the second generation of persons born and continuously maintaining a habitual residence therein, if such person has the nationality of such other state."(Harvard law review)

As evidenced by Harvard University plan, this plan supports conditional apply of the blood principle and does not grant citizenship to second generation immigrants because the social and cultural bonds no longer exist between government and citizens.

Project designers have interpreted the article as written:

"The nationality laws of most states which are based solely or principally on jus sanguinis contain no limitation upon the acquisition of their nationality by descendants of their nationals born abroad. Thus the nationality of such states may be transmitted indefinitely to successive generations of persons born and continuing to reside abroad." (The Harvard Research in international law, 1929)

Indeed by the laws of some states, nationality is conferred on descendants of their nationals without any limit as to the number of generations.

Relate to conditional application of jus sanguinis, can say that:

"This means that if X emigrates from the territory of state A to the territory of State B, X's child and X's grandchild may be given A's nationality jus sanguinis, but X's great-grandchild may not be given A's nationality jus sanguinis if his father and grandfather were born and habitually resided in the territory of $\mathrm{B}$, and if the great-grandchild has the nationality of B at birth." (Ibid)

As described, countries have a different approach because of different legal systems in granting citizenship to the next generations of citizens who have immigrated to other countries.

Austrian nationality

Legislation is based on the principle of jus sanguinis. While birth in Austria does not constitute a claim to the acquisition of citizenship at birth by descendents of immigrants, Austrian nationalities is attributed to children of Austrian nationals living abroad by virtue of descent. With respect to the attribution of nationality jus sanguinis to children born abroad, Austrian nationality legislation does not contain any restrictions, so that Austrian nationality 
may be indefinitely attributed to descendents of Austrian emigrants. This intergenerational transmission will only be prevented if parents of Austrian origin have renounced their Austrian nationality before the birth of the child in order to acquire the nationality of their (foreign) country of residence. Since 1999 retaining Austrian nationality has been made easier so that we can expect more jus sanguinis acquisitions abroad as a consequence. If the first generation retains Austrian nationality, then all subsequent generations can pass on their nationality acquired at birth to their own children. (Baubo"ck et al., 2006 B)

United States of America also uses this apply of the blood principle as follows:

For example, if a child is born outside the United States American citizenship will be paid to the child if the parents before the birth of her children have lived for a time in the United States. This time when the child's parents, both are citizens of America have not been specified and legislator just postulated that at least one of the parents have lived awhile in America before the birth of a child but in the case that one parent of child is American and another one is foreign the American parents are required before a child is born to have lived in the United States at least 5 years Provided that at least 2 years from 5 years is Fourteen years after the birth of the child But this time about the children who were born in America has increased after November 14, 1986 And now they must live 10 years in the United States and at least 5 years of this 10 years must be after the child is 14. (Azizi, 2009)

Before the 1981 Act came into force in UK, there had been various statutory provisions enabling British people with a UK connection to pass on their citizenship to children born outside the UK. These were now replaced by rules intended to limit citizenship by descent mainly to the first generation born abroad. But again there had to be exceptions. The long-standing rule that children born to parents in Crown service abroad would be nationals was preserved: it was therefore possible that a 'citizen by descent', born abroad, could pass on citizenship to a child born abroad if he or she was a diplomat or serving in the armed forces. Again, when that child grew up, he or she would be able to pass on citizenship if in Crown service abroad at the time of the birth. The new rules on descent included mothers as well as fathers for the first time. (Baubo"ck et al., $2006 \mathrm{~B}$ )

As some of the dual apply of blood principle was mentioned as conditional and absolute we must say that the absolute apply of blood principle has its own flaws as the use of the blood principle has its own associated Benefits. It should be noted that the drafters of the Harvard plan also admitted to the fact that the rule contained in article 4 of the plan has not become a rule of customary international law but it is offered only as a recommendation to make changes in the laws of countries which send and receive immigrants.

This project will determine that in what situations countries should not grant their citizenships Based on the blood principle to the second-generation immigrants who were born outside the borders of this country.

The Norwegian law of nationality of August 1, 1924, Sec. 9, reads in part as follows (translation):

"A Norwegian man or Norwegian unmarried woman who was born abroad and who has never resided in Norway shall be deemed to have ceased to be a Norwegian subject when becoming 22 years of age. The King, or the person authorized thereto by the King may, however, grant a certificate for the retention of the nationality."

Provisions similar to that last quoted are found in the nationality law of Denmark of April 18, 1925, Section 6, in the law of Finland of June 17, 1926, Section 2, in the law of Iceland of Iceland of June 15, 1926, Section 6, and in the law of Sweden of May 23, 1924, Article 9. (The Harvard Research in international law, 1929)

\section{The Absolute Apply of Blood Principle in Iran}

With Review of the citizenship laws in Iran that has been studied in Volume II of the Civil Code of Iran, 976 to 991 we reach the conclusion that Iranian legislator has followed absolute apply of the blood principle that is, an Iranian person can pass the citizenship of Iran to the next generation

Article 976: "The following persons are considered to be Iranian subjects: Clause 2: Those born Iran or outside whose fathers are Iranian."

Anyone who has an Iranian father and whether they have been born in Iran or in the State the provisions of this section can be concluded that any Iranian person residing abroad can transfer the citizenship of Iran to future generations. For example a family called X immigrated to America in 1950 and resided there Without leaving Iranian citizenship However, according to the absolute apply of blood principle her children will have Iranian citizenship generation after generation.

Previously, French rules on the granting of citizenship in such cases have no ruling. French law in 1927 granted French citizenship to the children of French parents of a legitimate inside or outside the territory of France (Article I), but this law has a part in granting French nationality in such cases is as follows: 
But this policy was changed in 1973 citizenship law according to new regulations, children born abroad from French parents will benefit from the citizenship of this country if they register their child's name with the competent French authorities (including the French consular authorities) (Azizi, 2009)

\section{Conclusions}

Nationality is an important issue in governments' and their national's international relationships. It is because that the stats define their nationals, rights and obligations and protect them in international domain.

In the absolute apply of blood principle transmission of citizenship is through descent to countless generations of the individual citizen not even the descendants who are born in the country, not even for a short stay where they reside there.

While In the absolute apply of blood principle transmission of citizenship through the blood principle to the second generation of citizens who have migrated is associated with the provisions

Resorted to in clause 2 of Article 976 of Iran's civil law, the blood principle is applied in granting citizenship but the Iranian legal system uses the absolute apply of blood principle and imposes some conditions in this context. France also uses the conditional apply of blood principle follows that France granted French citizenship before the 1973 citizenship law as absolute as to countless generations of citizens but has used from the conditional apply of blood principle Since the passage of the law and the condition is such that parents should register their child's name with the competent French authorities.

Absolute implementation of Jus saguinis in nationality transferring to later generation has undesirable outcomes. One of these undesirable results is that by implementation of Jus sanguinis, persons who have not lived in a country even for a low period of time, are the nationals of that country and some duties and obligations are imposed to them. On the other hand these persons have not any emotional dependence to culture and conjunctions of that country. Therefore this is preferred to nationality transferring to the descents who immigrate to another country will be performed by some limitations.

\section{References}

Ameri, J. (1988). Private international law (2nd ed.). Tehran: Agah publication.

Azizi, S. (2009). Studying of Nationality. Lesson booklet, Private international law, Hamedan: Bu-Ali Sina.

Baubock, R., Ersbøll, E., Groenendijk, K., \& Waldrauch, H. (2006). Acquisition and Loss of Nationality Policies and Trends in 15 European States (1st ed.), Volume 1, Comparative Analyses. Amsterdam University Press (A).

Baubo“ck, R., Ersbøll, E., Groenendijk, K., \& Waldrauch, H. (2006). Acquisition and Loss of Nationality Policies and Trends in 15 European States (1st ed.), Volume 2: Country Analyses. Amsterdam University Press (B).

Mateos P., Longley P. A., \& O'Sullivan D. (2011). Ethnicity and Population Structure in Personal Naming Networks PLoS ONE 6(9), e22943. http://dx.doi.org/10.1371/journal.pone.0022943

Nasiri, Mohammad. (2001). Private international law (8th ed.). Tehran: Agah publication. 